International Journal of Engineering \& Technology, $7(2.29)(2018) 876-881$
SPC
Website: www.sciencepubco.com/index.php/IJET
Research paper

\title{
Web-Based Expert System for Optimizing of Traffic Road in Developing Countries
}

\author{
Abduraouf. B. Z. Alshetwi ${ }^{* 1,5}$, Riza Atiq Abdullah O.K. Rahmat ${ }^{1,2}$, Muhamad Nazri Borhan ${ }^{1,2}$, Shaban Ismael \\ Albrka Ali ${ }^{3}$, Hamza Imhimmed Mohamed Irtema ${ }^{1,4}$, Aboubaker Y. Y. Alfakhria ${ }^{1}$ \\ ${ }^{1}$ Smart And Sustainable City Research Centre [SUTRA], Faculty Of Engineering \& Built Environment, Universiti Kebangsaan Ma- \\ laysia [UKM] ], 43600 Bangi, Selangor, Malaysia. \\ ${ }^{2}$ Programme Of Civil Engineering, Faculty Of Engineering \& \& Built Environment, Universiti Kebangsaan \\ Malaysia [UKM], 43600 Bangi, Selangor, Malaysia. \\ ${ }^{3}$ Civil Engineering Department, Near East University, Nicosia/TRNC, North Cyprus, Mersin 10, Turkey. \\ ${ }^{4}$ Department Of Civil Engineering, Sebha University, Sabha, Libya. \\ ${ }^{5}$ Department Of Civil Engineering Higher Institute Of Science And Technology Zahra Libya. \\ *Corresponding Author: Abduraouf.1978@Gmail.Com
}

\begin{abstract}
In current times, the increase of road users using road traffic include street carriers, vehicles, pedestrians, buses and other forms of transportation, both individually or in combination, utilizing the universal means to travel. Vehicle regulation and laws governing traffic are traffic laws, whereas road rules are natural regulation and standards that might be advanced in time in facilitating the traffic flow to be methodical and well-timed in emerging countries. Experts of the traffic road system [TRSys] suggests a procedure for road traffic experts and offers supervision and ice advertising on selecting effective and suitable policies. The road traffic development in dealing with traffic-associated complications needs various wide-ranging knowledge and information achievable from road traffic sources for example written sources [books, manuals, technical reports and standards] and traffic expert opinions. A computer tool is utilized in developing the expert system is Web-based expert system Microsoft [PHP]. It is a dominant application containing all the essential services to construct a Windows or Web-based applications for instance expert systems quick and proficient tools. TRSys is an online consultant system in traffic safety to implement a road network in developing countries that can help engineers, consultants, contractors, civil engineering students, and decision makers. The usefulness of the expert system [TRSys] to give recommendations which are appropriate to Road Network for Developing Countries. Traffic Road System [TRSys] is an innovative system advanced in this research to aid junior engineers. It also helps decision-makers and students in identifying traffic complications in developing countries and consequently recommend the application of suitable solutions.
\end{abstract}

Keywords: Expert system; knowledge-based; traffic road

\section{Introduction}

Recently, the increase of road users' comprising foot-travelers, automobiles, street carriers, buses and other forms of transportation, either individually or in combination, utilizing the common way to travel. Traffic laws are laws that govern traffic and vehicle rules, whereas road rules are natural legislature and standards that might be advanced over time to help the systematic and welltimed traffic flow in developing countries. This system of experts [TRSys] suggests a procedure for road traffic experts and offers guidance and ice advertising selecting well-organized and suitable policies.

Urban transport complications have undesirable concerns on the development a nation's socio-economy. For instance traffic is one in respective key complications afflicting urban facility in most capitals worldwide [1]. The issues are credited to incessant urban population growth, non-public vehicle ownership, ineffectual management of traffic system and public transport services incompetence causing traffic congestion with calamitous significances. The quantity of journeys on metropolitan space and high- ways networks significantly recently in several developing countries' cities world over. Similarly, it did not sustain the road network's capability with demand of travel arising. Urban roads networks in a number of busy countries are severe which leads to improved travel times, and rise the number of stations, and unexpected delays, increased travel prices, inopportuneness to drivers and passengers, heightened pollution and noise, and surge in the traffic accidents occurred [2].

Traffic offers urban convenience and fast service for passengers and providing entrance to the trend, instead of getting to the destination. It regularly costs passengers some time to reach their final destination. Certain owners of private cars illegally utilize their cars as taxis to make money to meet the passengers final distance demand between the bus station and the trains and the final destination. As the government struggle to run through more and more bus service, it still requires improvement as passengers preferring illegitimate taxis occupying part of the whole [3].

An expert system is a user program inference technique involving formal reasoning normally executed by a human expert in solving complications in a specific area of information. The expert system has the ability to give advice, make diagnosis, analysis and catego- 
ries utilizing earlier distinct knowledge base. The base of knowledge is a gathering of rules and facts. Expert system rules are founded on transportation networks' universal knowledge and road intersections characteristics will be able to be the smart solution. Definition of consecutive procedures by the rules will inevitably instate road intersections turn information, as an alternative to manual effort. The study's aim is building an expert system to optimize the road network to developing countries. Expert systems are smart information system that performs, in a certain sense, as a human expert in the application domain [4]; [5] \& [6]

\section{Literature Review}

\subsection{Expert System Civil Engineering}

Expert System is a current information technology skill obtained from the field of civil engineering's artificial intelligence research decades ago. The development was to mimic or replicate smart air pollution issue and noise in a computer program. The expert system application for this area quickly increasing. Consequently making its relevance to the civil engineering field. Numerous expert systems were lately advanced in the transportation engineering field.

\subsection{Comix}

Blending is an expert system revolving around practices implemented based on concrete mix [Abdullahi, Al-Mattarneh, Hassan, Abu Hassan, \& Mohammed, 2008] which has been designed to cater for consultants, design engineers, and real technologists. The system is founded on New Zealand professional guideline for concrete mix. It recommends the amount of water for particular strength of cement and estimates the quantity of adhesive. It advises on the amount of sand used and estimates the total mass of the concrete. This system is developed in New Zealand Central Laboratories [Salam, Islam \& Rashid, 2012].

\subsection{CWQM}

[Ooshaksaraie \& Basri, 2011] designed CWQM, an expert system for creating water quality surveillance by utilizing Microsoft Visual Basic. The main aim of the system is to decrease pollution of building sites by storm water. Apart from its primary function [decision support system], this expert system has the potential to be used for teaching junior civil engineers and students. It shows the water quality surveillance system in report form, water sampling places in GIS format, and water quality surveillance information in graphs. CWQM gives precise decisions for construction projects which solely pays attention on decreasing storm water contamination.

\subsection{TSST}

[Ooshakasaraie, Basri, Bakar, \& Maulud, 2012] had created an Expert System for Temporary Soil Stabilization on Commercial and Residential Building Grounds in Malaysia by utilizing Microsoft Visual Basic for choosing an interim ground stabilization method in residential and new township construction projects. This expert system helps local government to administer building plans and analyze building grounds thoroughly. It shows a sediment and erosion control plan in report format. Extensive TSST utilized in such a way can give more precise and goal-oriented choices on building plans focusing on sediment and erosion control plans.

\subsection{System For Maintenance Of Highway Concrete Bridge In Greece}

[Chassiakos, Vaggiotas, \& Theodorakopoulos, 2005] created a knowledge-based program to ease decision making in the field of management planning for expressway concrete dredges in Greece. This expert system is made of three parts. The first part is made to focus on upkeep, the second function is to recommend suitable treatment and plausible choices for support and the final part will fix management of bridge stocks. The input information consist of three kinds of information. The first data is gained from the assessment of bridge and second on the condition inspection. The third is the information that provides answers for the upkeep.

\subsection{MCESC}

[Al-Ani, Sidek, Desa, \& Basri, 2012] created a hybrid knowledgebased expert system [KBES] that is known as Multi-Criteria Erosion and Sediment Control system [MCESC], that has the capability to point out the most efficient storm water managing measures that revolves on precise characteristic and the weight of the experiment. Information from road building plans in Malaysia were used in experimenting the efficiency of MCESC in providing answers to real sediment and erosion control issues. The MCESC was programmed with Visual Basic. It can be utilized by engineers, contractors and executives in developing a sediment and erosion control blueprint and an environmental management blueprint to be used in Malaysia.

\subsection{Expert System in Transportation Engineering}

Multiple expert systems had just been created in the area of transportation engineering. A few of them are listed below.

\subsection{Development of a Rural Road Safety Audit Expert System [RRSAES]}

Ewadh [2005] had developed an expert system to carry out rural road safety review in Iraq. This knowledge-based expert system's function is to determine security risks based on RSA rules. A list of rural road safety review had been utilized to create the knowledge base of this program. The knowledge base of this plan is programmed in Microsoft Visual Basic 6.0 software. The result of this scheme indicates the road safety reviews that determines the severity of the road safety features.

\subsection{Atlces}

[Wen, 2008], programmed a knowledge-based expert system known as DATLCES to automatically administer and adjust the cycle range of traffic lights in urban areas. DATCLES is used along with a stimulation model that is made of six sub sections to provide assistance in studying traffic issues. This expert system can stimulate the time of arrival and departure of motor vehicles at intersections and provide the time and phase settings for traffic lights.

\subsection{USLIMITS2}

[Srinivasan, Harkey, Tharpe, Sumner, \& Parker, 2008] made USLIMITS2 as a web-based expert system for providing reasonable speed barriers on US expressways based on the Federal Highway Administration [BIWA] regulations. The expert system is developed based on the findings drawn from past studies along with responses from users of the present USLIMITS program created by the Australian Road Research Board, a study of present speed zoning regulations and the need to enhance and help users by providing reasonable speed limits for precise locations and traffic situations. The program was precisely created to offer expert resource data revolving on logic utilised by professionals in United States.

\subsection{Micro PAVER}

Designed by the US Army Corps Engineers, Micro PAVER is a pavement management expert system created to help engineers in 
the maintenance of military roads. The objective of Micro PAVER is to run on personal desktops while PAVER can function in mainframe computers. Micro PAVER is utilized to administer roads, streets, airfield pavement, and parking lots. Micro PAVER has a plan that allows it to focus on projects based on real elements such as the funds available, type of repair, cost of repairs and cost of maintenance [Ismail, Ismail \& Rahmat, 2009].

\subsection{ES-DFMP}

Ismail et al. [2009] proposed the design of an object-oriented expert system, which can be applied for maintenance and rehabilitation of the airport pavements. The method describes the distresses of the airport pavement, specifies the causes, predicts the future behavior of the pavement, designs overlay rehabilitation strategies and estimates the unit cost of the activities. This system uses the Kappa-PC as an expert system shell.

\subsection{ES-APAM}

Ismail et al. [2009] suggested that the foundation for an objectoriented expert system that can be implemented for maintenance and rehabilitation of the airport pavements. The technique addresses the issues of airport pavement, narrows the reasons, estimates the characteristic of the pavement in future, provides rehabilitation techniques and provides a rough calculation of funds required. This system utilises the Kappa-PC as an expert system model.

\subsection{Knowledge-Based Expert System for Intersection Improvement [ESII]}

[De Guzman \& Sigua, 2009] crafted a knowledge based expert system to upgrade safety measures taken at intersections. The objective of this expert system is to replace micro-simulation programs in enhancing road safety at intersections because of the increased funding for software calibration-validation related issues. The goal of designing this system is to upgrade intersections by reducing number of traffic accidents and congestions. This technique is beneficial to consultant and civil engineers, government agencies and students. The result obtained by this plan is a solution for the negative implications of accidents and congestion issues at intersections. Moreover, the reason for these issues can be identified and examined for future use in upcoming projects.

\subsection{E-ASSIST}

[Mansyur, Rahmat Ismail, \& Kabit, 2011] designed an expert system to help engineers in the application of related transportation demand management [TDM] techniques based on what was referred to by domain experts as E-ASSIST. The procedure of sorting present data on transportation management market techniques and also the procedure that proceeds to the choice of one or more suggested techniques is programmed in KBES shell that is programmed using Kappa PC version 24 , that uses object oriented and high graphical user interface. The input for the system is gained from multiple sources such as research journals and books. E-ASSIST can be utilized to ease making choices and as a teaching tool for private developers, government officials and apprentice transportation engineers.

\subsection{ES-HGDesign}

[Syamsunur, Ismail, Atiq, \& Karim, 2011] designed a knowledgebased expert system to help transportation engineers regarding issues pertaining to expressway geometric design known as ESHG Design. It uses the geographical information system that takes into account the elements that influences the decision of a safe, conducive and cost-friendly route. ES-HGDesign was programmed based on object-oriented process using Kappa-PC.

\subsection{COPRBU}

CORPBU is a knowledge-based expert system programed to overcome issues related to routes and schedules of public transportation system. It is used in the administration of operational problems of public buses in Baghdad, Iraq. Information was obtained from books and questionnaire surveys conducted on users and person-in-charge of public buses. One hundred survey forms were filed and given to bus users at several bus stations. Each questionnaire has multiple questions concerning the level of services offered by public buses. The expert system is designed using Microsoft Visual Basic. This system is created for the administration of public transportation in Baghdad [Mosa, Taha, Ismail, \& Rahmat, 2013].

\subsection{SP-SPEDA}

[LADIN, 2014] Sustainable development expert system for urban transport strategy is known as Sistem Pakar untuk Strategi Pengangkutan Bandar Mapan [SP-SPEDA] in Malay. The main aim is to provide professionalism and sustainability of urban transport by means of computer based applications for engineers and transportation, private transportation engineers and planners who are inexperience and lack technical knowledge. Besides, new engineers may encounter different issues, for example, the insufficient time to acquire and process data. The techniques utilized to get the data for the creation of SP-SPEDA application are awareness of field knowledge by the engineers, extracting useful data from reference books and magazines, field visitations and finally interview with dominant professionals. Professionals can utilize this system for sharing of knowledge. This expert system is designed using Microsoft Visual Basic. The confirmation of the system by multimedia professionals and verified by domain professionals.

\subsection{CALMSYS}

[Falamarzi, Borhan, \& Rahmat, 2014] designed a web-based advisory expert system for carrying out traffic reducing techniques in housing areas. It was designed, validated, and verified to help endusers especially safety consultants, students and transportation engineers. This expert system was programmed in the Civil Engineering Department of the National University of Malaysia Alrubaih et al., [7]. This expert system is programmed using Microsoft Visual Basic. This technique is validated by computer professionals and verified by domain professionals. They reviewed the system with excellent grades for credibility of system efficiency and reliability of the results.

\section{Methodology/Materials}

The current study defined the system as the traffic roads system [TRSys] advanced by agreeing to standard knowledge-based expert system development approaches. The programming language utilized in developing the PHP system providing superior tractability and adaptableness to develop this prototype rapidly. This tractability permits the knowledge engineer presenting the domain knowledge more easily. On the other hand, the development of programming languages need more time as the developer must first familiarise himself/herself with the computer jargons and must still improve the program codes. Furthermore, program debugging is often challenging [D. Waterman, 1986]; [Terry, 1991] $\&$ [Islam, 2004].

\subsection{Knowledge Acquisition}

The acquisition of knowledge is possible from varied bases such as textbooks, guidelines, reports, the Internet, and the human expert as the most significant [Durkin \& Durkin, 1998]. To develop the current expert system's knowledge base, numerous knowledge sources have been referred and combined. Figure 1 exemplifies 
the knowledge attainment flow diagram. The following sections will display these sources and give a thorough explanation for each.

\subsection{Selection of Building Tool}

The use of Microsoft PHP in establishing TRSys [expert in implementing road system's traffic strategies]. PHP offers a set of tools needed when building a user interface. Furthermore, PHP offers the ground rules that could be programmed in mathematical language and logical expressions swiftly. Microsoft PHP is an influential presentation containing all the essential facilities in building a Windows or Web-based applications for example expert systems swiftly and competently and tools.

In 1995, PHP expansion began when Rasmus Lerdorf code a number of Common Gateway Interface [CGI] programs in $\mathrm{C}$ [Lerdorf, Tatroe, \& MacIntyre, 2006] that he utilized in maintaining his private website. The extension work with web forms and to interconnect with databases, calling this application "Personal Home Page/Forms Interpreter" or PHP/FI.

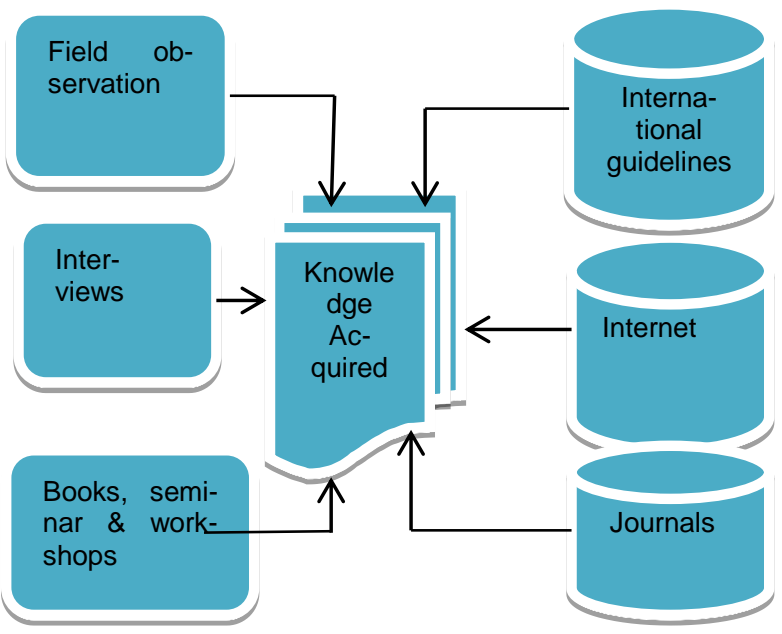

Fig.1: Knowledge Acquisition Flow Diagram

PHP/FI can aid in building modest, vibrant web applications. In the process of accelerating bug reporting and improving the code on June 8, 1995, Lerdorf originally proclaimed PHP/FI released as "Personal Home Page Tools [PHP Tools] version 1.0" on the Usenet discussion group comp cgi. This release had already PHP basic functionality from 2013. This includes the ability in embedding HTML, form handling and Perl-like variables. The resemblance of syntax that of Perl but was less complicated, more restricted and inconsistent [Group, 2010].

Leadoff had no intention to make the original PHP to be a new programming language, but it organically grew, with Leadoff commenting that he did not have any idea on how to stop it, as writing a new programming language was not the main intention. A development team started to form and, after months of work and beta testing, PHP/FI 2 was formally released in November 1997. PHP is deficient in innovative overall design but as a substitute, it is organically advanced and led to the unpredictable functions naming and unpredictable parameters ordering. In certain circumstances, the selection of function names match the lower-level libraries which PHP wrapped whereas in certain initial PHP versions, as hash functions, the function names length was internally used, thus chosen names were to improve the distribution of hash values.

It is an unassuming issue in embedding web pages' dynamic activity when you pages were given with PHP. PHP extension has straight permission into scripting language. Writing is needed from the perspective of a developer. There are also various ways to format and output PHP information. The situation such with PHP is that web developers despite not in equal speed amassing code in $\mathrm{C}$, or a relative language have scripting language. And it is extremely immediate, plus it assimilates faultlessly with HTML markup [Nixon, 2014].

\subsection{Knowledge Representation}

The usage of attained knowledge is a symbolic representation of dealing with an automatic means over the logic expert system. The usage of Microsoft PHP in this study to construct of the suggested expert system.

The suggested technique in this study is an expert system for detection of problems and users guide over diagnosis process. Understanding on these challenges can be characterized in the form of rules. In studies of roads traffic, when security issues arise, the part of experts and engineers is collecting the essential evidence on the issue. The subsequent step is the process of decisionmaking. Consequently for this base system expert, the forwarding inference engine sequence is adequate as an alternative of episodic back. Logic rises from the information given and carrying on with it. This method is be governed by the IF-THEN relations. To be precise, if it matches IF condition in a general rule, procedures in the THEN side should be applied. This procedure can be displayed as IF [the case], then [the conclusion]. The assembly of rules is possible by engaging connectivity terms, including OR, AND another forming a combined rules or the vehicle rules. Table 3.3 exemplifies certain production that has been utilized in [TRSys] rules.

\subsection{Expert System Architecture}

The most demanding, perplexing and arduous task in expert system development is the system architecture [Durkin \& Durkin, 1998] \& [Basri, 1999]. As a knowledgeable engineer, it is indispensable to gain a good understanding of the domain so as in improving the prototype building with respect to its viability and valuation [Basri, 1999]. Attaining engineering skills and knowledge can also be considered as step one for the capable engineer. The use is to obtain this mission before emerging as being conscious of the field and the elemental technological expertise, and the mixture is to be expected as part of a multi-standards evaluation process supplements, in addition to getting the right understanding of the Department of Transportation. This is primarily regarding air pollution and noise from historical knowledge, and estimating the lifestyles price cycle of the more than a few best practice administrative. Important sources of materials are as follows:

a. Textbooks' revision and guidelines, and detailed evidence on improvement of expert system methodologies, and the optimizing impact of road network peak times effects and other times.

$b$. Seminars participation, and conference proceedings from national and international casing numerous topics for example congested traffic, transport, ecological pollution, and transport administration and communications as a whole, several analysis procedures with diverse applications and standards.

c. Review of the numerous expert systems architecture developed in numerous fields.

d. Review current information in the development of an expert on a number of topics connected to transport administration and communication system model.

$e$. Reassessment of numerous standards of diverse analysis procedures and practices, and data entry, data analysis, and userfriendliness. The acceptance of multi-criteria analysis techniques to technologies associated with transport and shift impact, and ecological management.

The expert system is a form of a computer program representing and reasoning with knowledge of certain specialist subject as it solves problems or gives advice. The expert systems building process is normally referred to as knowledge engineering. The involvement of the knowledge engineer with the expert system's entire components. Generally, building expert systems is an iterative procedure. Refining the components and their interaction will be over the course of the knowledge engineer's numerous meet- 
ings with the experts and user [Saba, Rehman, \& Elarbi-Boudihir, 2014].

TRSys structure is described in this section consisting of a graphical user interface, working memory, inference engine, and knowledge base. The building of the system structure by the knowledge engineer is with the acquisition of knowledge and reasoning approaches from written sources and the domain experts' first set. Figure 2 displays the TRS components and the development team relationships.

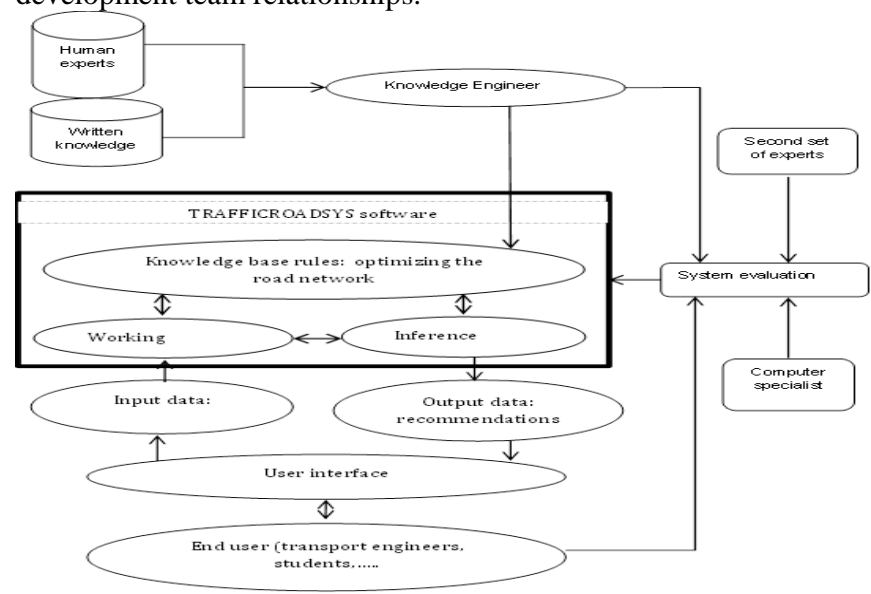

Fig.2: The structure of TRSys

\subsection{Graphical User Interface}

A graphical user interface [GUI] is a human-computer interface [interaction between humans and computers] utilizing windows, icons and menus and is made possible with the use of a mouse [and usually to a restricted degree by a keyboard too]. It is a form of user interface allowing interaction of users with electronic devices over graphical icons and visual indicators for example secondary notation, in place of text-based user interfaces, typed command labels. Figure 3 displays the chief menu screenshot. This section discusses tool boxes' function for traffic road system, home, problems and solutions, beneficial articles and admin login. User interface Traffic Roads System [TRSys] is fun and easy to use. Clear and attractive which can facilitate the utilization of the system. The design consists of some controls such as text boxes this framework. Groups, buttons, and labels. Option buttons, dropdown menus. Image funds. Video commands boxes and boxes

\subsection{Toolbox for Traffic Condition}

The interruption of traffic by traffic or the usage of highways or subways causes traffic congestion in busy roads, traffic lights, busy intersections. Road traffic intimidates the road users' safety and has adversative effects on the environment for example air pollution and noise. Described and presented to users in Figure 4. Impact of roads on the environment [positive and negative alike] are the influence of local roads [highways], for example noise, air, and water pollution. Other influences comprise vehicles emissions causing climate change. Design, construction and roads management and parking lots and other associated facilities, along with the vehicles design and organization can be utilized to reduce the effects. Road noise can be an annoyance if it invades on populated areas, particularly roads at higher operating speeds located near intersections and on uphill sections. Noise health influence can be expected in locations involving road systems utilized by large numbers of motor vehicles. Toolbox for problem in increased air pollution and noise in the major road complications, were previously described and presented to users in Figure 5.

Technological solutions have the potential of delivering important remunerations. For the time being, a switch from petrol technology which has great potential, mostly over turbocharging an engine for better fuel efficiency will be of assistance. Enhanced vehicle upkeep and eco-driving can also make a real variance. A move to natural gas and hybrid petrol-electric vehicles in the future -there are a greater variety of more strongly appraised selections accessible enabling mass-market-helping lessening air pollution. Furthermore, the fleet natural turnover will lead to an increasing number of vehicles on the roads complying with the newest standard. Ultra-low-carbon [for instance, pure electric] vehicles will aid with this battle in the long term. Solutions formerly defined are shown to users as revealed in Figure 6.
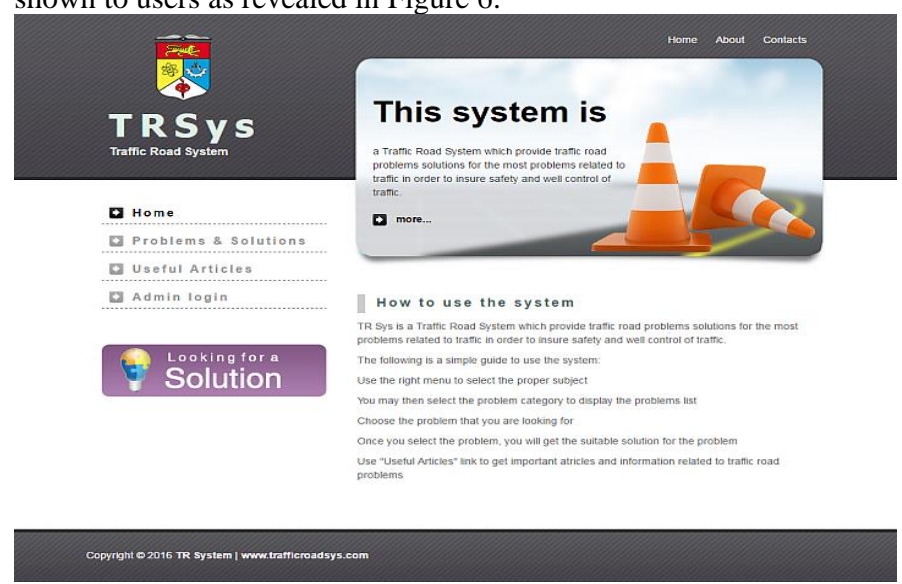

Fig.3: A screenshot of the TRSys main menu.

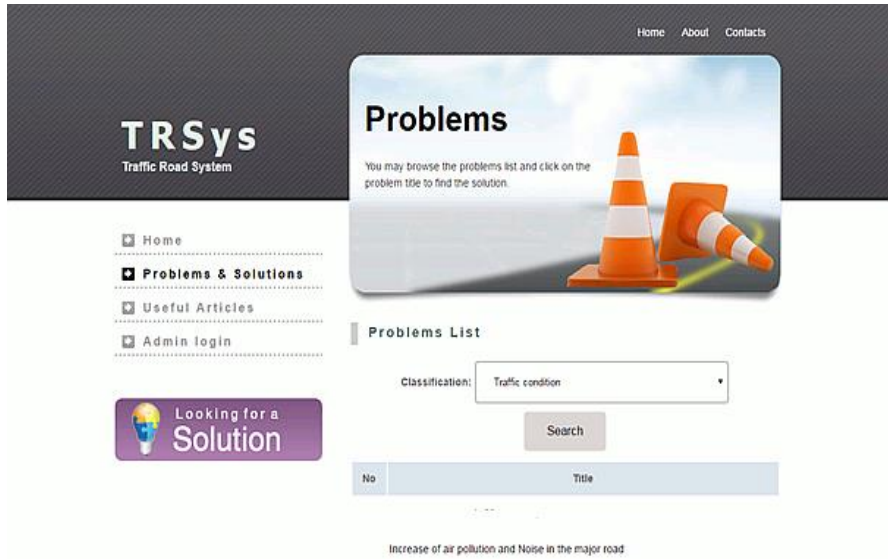

Fig.4: A screenshot of the problem for traffic condition

Toolbox for Problem and Solutions in Increase of Air Pollution and Noise in the Road

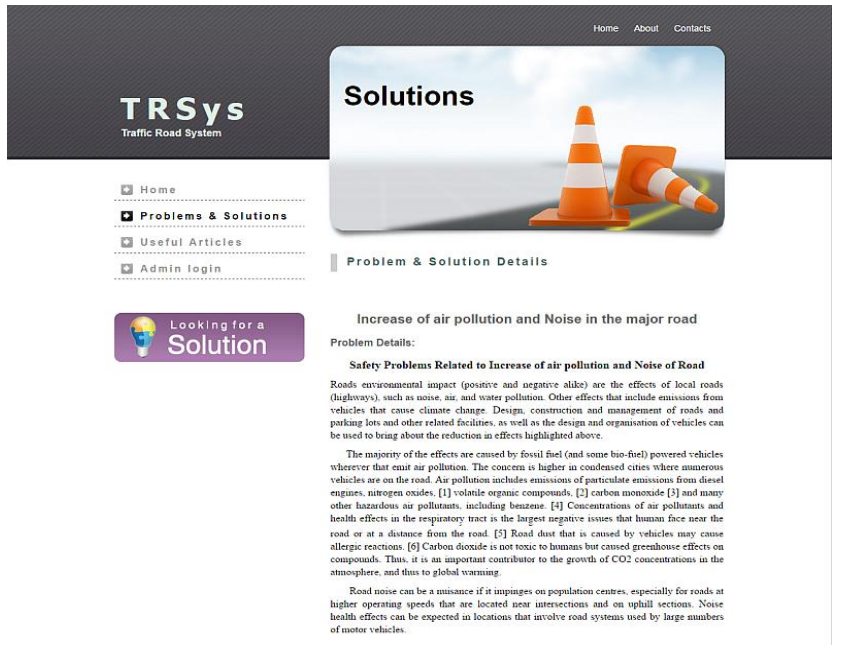

Fig.5: A screenshot of the problem page 


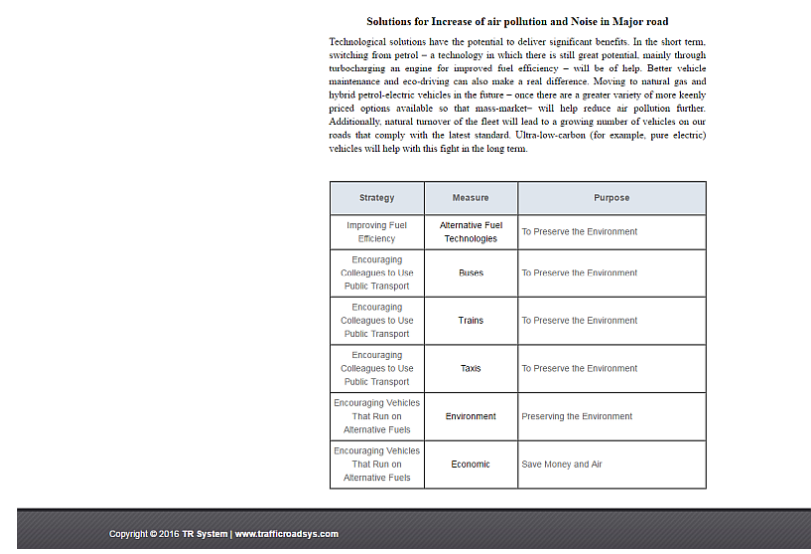

Fig.6: A screenshot of the solutions page.

\section{Conclusion}

Web-Based Expert System to optimize Traffic Road in developing countries traffic road system experts [TRSys] in this study suggests a procedure for road traffic experts and offers guidance and ice advertising on selecting effective and suitable policies. The road traffic development dealing with traffic-related problems needs numerous wide skill and knowledge achievable from road traffic sources for example written sources [books, manuals, technical reports and standards] and traffic experts' opinions. The use of a computer tool in developing the expert system is Web-based expert system Microsoft [PHP]. It is a dominant application containing essential abilities in building a Windows or Web-based applications for instance expert systems and tools rapidly and competently. TRSys is an online consultant system to implement a road network to develop countries assisting engineers, consultants, contractors, civil engineering students, and traffic safety decision makers. This expert system [TRSys] is beneficial to give commendations appropriate to Road Network for Developing Countries. Traffic Road System [TRSys] is a new system advanced in this research to aid junior engineers. Decision-makers and students are to recognize developing countries traffic complications and apply accordingly suitable solutions to intensify air pollution and noise on major roads.

\section{Acknowledgement}

The author would like to thank the Sustainable Urban Transport Research Center [SUTRA], UKM and Higher

Institute of Science and Technology / Zahra, Tripoli, Libya who provided all the facilities for this research.

\section{References}

[1] Yildirim T, Gülseren O, Lynn J, Brown C, Udovic T, Huang Q, et al. Giant anharmonicity and nonlinear electron-phonon coupling in $\mathrm{MgB}$ 2: a combined first-principles calculation and neutron scattering study. Physical review letters. 2001;87[3]:037001.

[2] Edara PK. DYNAMIC TRAVEL DEMAND MANAGEMENT STRATEGIES: Dynamic Congestion Pricing and Highway Space Inventory Control System: Virginia Polytechnic Institute and State University; 2005.

[3] Wu sZ, Yang J, Huang L. Study on the collision avoidance strategy at unsignalized intersection based on PreScan simulation. ProcediaSocial and Behavioral Sciences. 2013;96:1315-21.

[4] Michie D. Expert systems in the micro-electronic age: Edinburgh University Press Edinburgh; 1979.

[5] Goodall A. The Guide to Expert Systems, Learned Information Ltd. Oxford, England; 1985.

[6] Waterman DA. A guide to expert systems: Addison-Wesley; 1986.

[7] Alrubaih M, Zain MFM, Alghoul M, Ibrahim NLN, Shameri M, Elayeb O. Research and development on aspects of daylighting fundamentals. Renewable and Sustainable Energy Reviews. 2013;21:494-505. 